\title{
Rock Dynamic Fracture Characteristics Based on NSCB Impact Method
}

\author{
Yanbing Wang $\mathbb{D}^{1,2,3}$ \\ ${ }^{1}$ School of Mechanics and Architecture Engineering, China University of Mining and Technology (Beijing), Beijing 100083, China \\ ${ }^{2}$ State Key Laboratory for Geomechanics and Deep Underground Engineering, Beijing 100083, China \\ ${ }^{3}$ Department of Mechanical Engineering, University of South Carolina, Columbia, SC 29208, USA
}

Correspondence should be addressed to Yanbing Wang; ceowyb818@163.com

Received 2 December 2017; Revised 12 March 2018; Accepted 20 March 2018; Published 21 May 2018

Academic Editor: Sergio De Rosa

Copyright (C) 2018 Yanbing Wang. This is an open access article distributed under the Creative Commons Attribution License, which permits unrestricted use, distribution, and reproduction in any medium, provided the original work is properly cited.

\begin{abstract}
In 2012, the International Society for Rock Mechanics (ISRM) recommended a new Notched Semicircular Bend (NSCB) method for the determination of dynamic fracture toughness of rock materials, but it did not consider the effect of some uncontrollable factors in the course of the experiment on the test result. This thesis firstly carried out dynamic fracture toughness experiments on several typical rock materials such as sandstone using the modified Split-Hopkinson Pressure Bar (SHPB) experimental system with high-speed photography, directly compared the dynamic fracture failure characteristics of several rock materials, and examined the loading rate dependency of the dynamic fracture toughness of rock materials. Based on the numerical analysis method of Discrete Lattice Spring Model (DLSM), it focused on the effect of bullet impact loading rate, loading area of incident bar, support restraints of clamping specimen, and other uncontrollable factors in the course of SHPB experiment on test results. The findings can be referenced for the improvement of NSCB method.
\end{abstract}

\section{Introduction}

In rock engineering practice, the action of dynamic loading is a commonplace, including engineering blasting, earthquake, or rock burst [1-4]. For the engineering safety and the maximization of economic benefits, the mechanical properties of rock such as dynamic fracture toughness have to be accurate in the design and construction of these projects $[5,6]$. As the dynamic experiment is more complex than static experiment with respect to the rock materials, in 2012, the Committee of Rock Dynamics of International Society for Rock Mechanics (ISRM-CRD) first recommended some methods for rock dynamic experiment, including Notched Semicircular Bend (NSCB) for the testing on dynamic fracture toughness of rock materials [7]. Wei et al. [8] estimated theoretically the lengths of fracture process zones (FPZs) in the NSCB and CCNSCB tests with representative specimen geometries using the maximum normal stress criterion, and their effects on these fracture toughness tests were evaluated according to the effective crack model. Wang and Yang [9] tested the dynamic fracture toughness of coal samples based on the
Notched Semicircular Bend (NSCB) method under an impact load and discussed the influence of the impact velocity and bedding angle on the dynamic fracture toughness, failure strain, and strain rate of coal samples. Yao et al. [10] studied the effect of thermally induced damage on the dynamic fracture toughness of two mortars. The Notched Semicircular Bend (NSCB) specimens were heat-treated at 150 degrees C, 250 degrees C, 350 degrees C, 450 degrees C, and 600 degrees $\mathrm{C}$ and then tested at room temperature of 25 degrees C with a Split-Hopkinson Pressure Bar (SHPB) apparatus. Chen et al. [11] selected the NSCB method to investigate the fracture initiation toughness of rocks subjected to preload. Wei et al. [12] determined the critical SIFs for a wide range of CCNSCB (cracked chevron notched semicircular bending method) specimen geometries via three-dimensional finite element analysis. Gao et al. [13] measured more fracture parameters of the NSCB specimen loaded by a SHPB system using the digital image correlation (DIC) method combined with ultra-high-speed photography. Dai et al. [14] studied the micromechanical model for the rate dependence of the fracture toughness anisotropy of Barre granite based on 


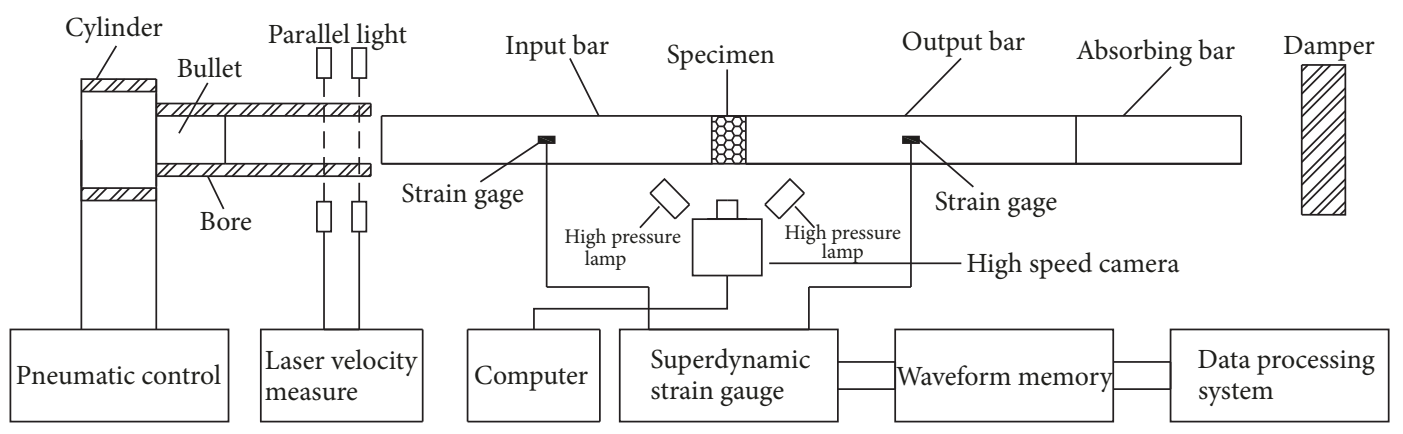

FIGURE 1: Diagram of SHPB experimental system.

NSCB method. Yin et al. [15] studied the effect of thermal treatment on the dynamic fracture toughness of Laurentian granite using NSCB method. This NSCB method is a test unit based on the modified Split-Hopkinson Pressure Bar (SHPB), but it does not consider the effect of bullet impact loading rate, loading area of incident bar, support restraints of clamping specimen, and other uncontrollable factors in the course of SHPB experiment on test results.

Based on the ISRM-recommended NSCB, the dynamic fracture toughness of several typical rock materials including sandstone was determined here, and the effect of uncontrollable factors in the course of the experiment on test results was analyzed using Discrete Lattice Spring Model (DLSM).

\section{Test Unit and Principle}

The $\Phi 50 \mathrm{~mm}$ Split-Hopkinson Pressure Bar (SHPB) experimental system from State Key Laboratory for Geomechanics \& Deep Underground Engineering was used. It comprises pressure control system, bullet, input bar, output bar, absorbing bar, damper, laser speed measurement system, measurement recording system (ultra-dynamic strain gauge, waveform memory, and data processing system), and highspeed camera, as shown in Figure 1. This experiment was based on the following assumptions: (1) one-dimensional stress wave and (2) uniformity.

The specimen was clamped between the input and output bar, the incident wave $\varepsilon_{i}(t)$ was generated when the bullet impacted the input bar, and the action between the incident wave and the specimen generated the reflected wave $\varepsilon_{r}(t)$ and the transmitted wave $\varepsilon_{t}(t)$, where the waveforms will be recorded by strain gauges attached on the input and output bar. In the course of the conventional SHPB experiment, the majority of incident waves were rectangular with highfrequency oscillations, which indicates that the dynamic force did not reach equilibrium in early period of the loading. The contact force $P_{1}$ between the input bar and the specimen and the contact force $P_{2}$ between the output bar and the specimen were, respectively, as follows:

$$
\begin{aligned}
& P_{1}=E A\left[\varepsilon_{i}(t)+\varepsilon_{r}(t)\right], \\
& P_{2}=E A \varepsilon_{t}(t),
\end{aligned}
$$

where $E$ is the elastic modulus of bar material and $A$ is the cross-sectional area of the bar.

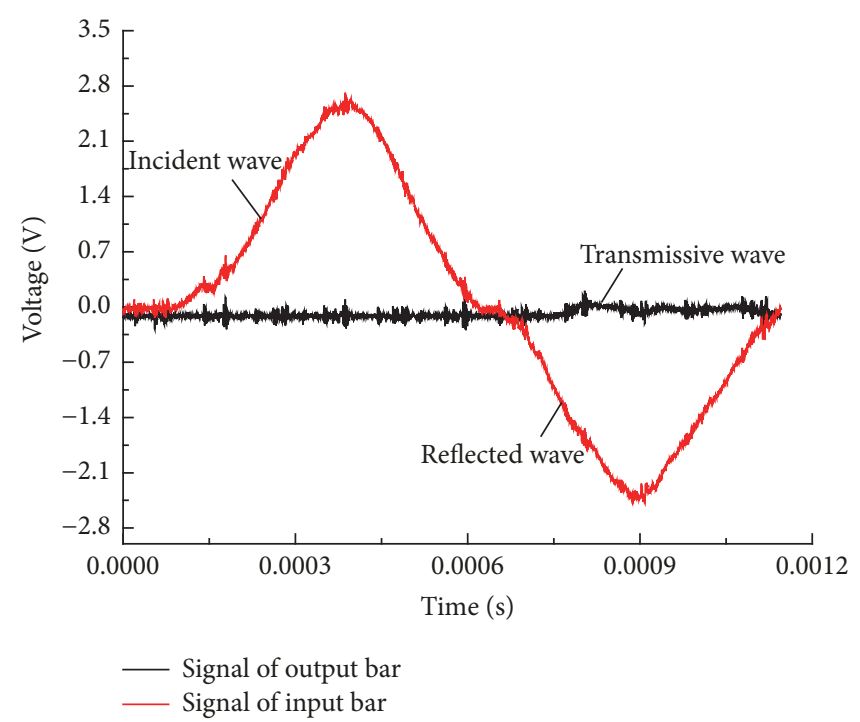

FIGURE 2: Output signals.

To make the dynamic loading on the ends of the specimen at equilibrium, $1 \mathrm{~mm}$ thick round rubber gasket was used as the pulse shaper to be attached to the end of the incident bar, resulting in a half-sinusoidal incident wave, as shown in Figure 2. The specimen was kept at the state of dynamic equilibrium before the failure, that is, $P_{1} \approx P_{2}\left(\right.$ or $\varepsilon_{i}(t)+\varepsilon_{r}(t)=$ $\left.\varepsilon_{t}(t)\right)$, which is the key to the success of dynamic loading experiment. The calibration of stress time-history curves at the ends of the specimen can be analyzed through comparison.

The experiment procedure was based on [16], and the dynamic fracture process of the rock specimen was captured with a high-speed camera. The test data was processed once the experiment was completed.

The dimension of NSCB specimen is indicated in Figure 3; according to the ISRM-recommended dimension [7], the diameter $D$, the thickness $B$, and the notch length $a$ for each specimen were 50,25 , and $4 \mathrm{~mm}$, respectively, and the distance $S$ between two supports was $30 \mathrm{~mm}$. Thus, the dimensionless quantity $\alpha_{a}=a / R=0.16, \alpha_{h}=h / R=1$, and $\alpha_{S}=S / D=0.6$.

The dynamic loading forces at the ends of specimen must be kept in balance. Figure 4 shows a typical dynamic balance 


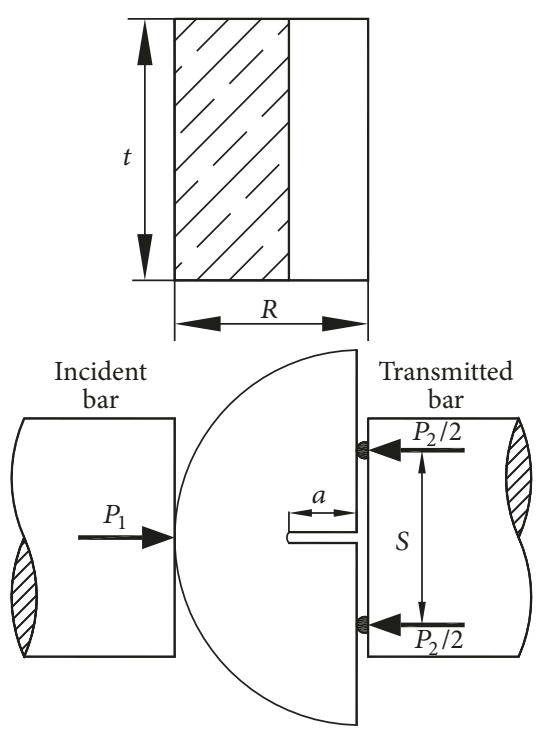

FIGURE 3: Dimension of NSCB specimen.

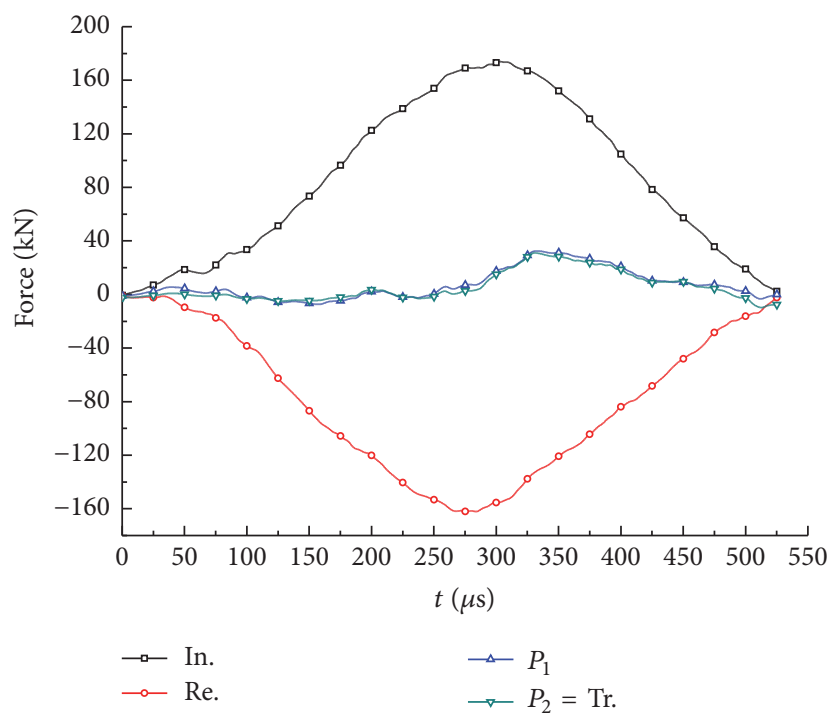

Figure 4: Dynamic force balance check.

check curve, and from (1), the dynamic loading force at the ends of the specimen was determined to be balanced.

The type $I$ stress intensity factor (SIF), $K_{I}(t)$, can be expressed as [7]

$$
K_{I}(t)=\frac{P(t)}{B R^{3 / 2}} Y\left(\alpha_{a}\right),
$$

where $R$ is the radius of a specimen and $Y\left(\alpha_{a}\right)$ is a dimensionless quantity, and its value is related to the geometric dimension of the notch; for $\alpha_{a}=0.16$ and $\alpha_{S}=0.6$ in this experiment, $Y\left(\alpha_{a}\right)$ can be expressed as

$$
Y\left(\alpha_{a}\right)=0.4444+4.2198 \alpha_{a}-9.1101 \alpha_{a}^{2}+16.952 \alpha_{a}^{3}
$$

The peak point of $K_{I}(t)$ curve was used as the dynamic fracture toughness, $K_{I C}$, which has a significant loading

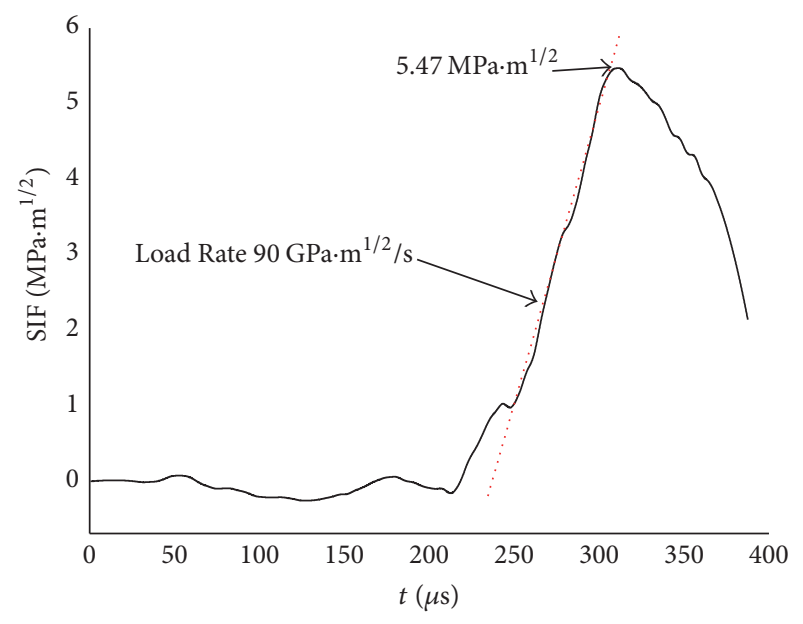

FIGURE 5: SIF time-history curve.

rate dependency [7], and the slope of the straight segment before the peak of SIF time-history curve was defined as the loading rate, and the loading rate as shown in Figure 5 was $90 \mathrm{GPa} \cdot \mathrm{m}^{1 / 2} / \mathrm{s}$.

\section{Dynamic Fracture Toughness Test for Several Typical Rocks}

3.1. SHPB-Based Dynamic Fracture Roughness Test. Five typical rock materials were selected and the basic physical and mechanical parameters were given in Table 1 .

3.2. Test Results and Analysis. Fastcam-SA5(16G) color highspeed digital camera produced by Japan Photron was used in the experiment. Figure 6 shows the process of rock specimen failure recorded by the high-speed camera. In view of the low gloss of the rock specimen, we have increased the brightness and contrast of some images by $40 \%$ and $40 \%$, respectively, for example, coal and PMMA. The cracks initiated from the notch and ran through the entire specimen within $10 \mu \mathrm{s}$, and the semicircular rock specimen was symmetrically split into two equal parts. The mineral particles in the sandstone were relatively smaller, and the trajectory of its crack propagation was relatively straight to almost split the specimen into two equal parts; the mudstone had good integrity and the trajectory of its crack propagation was bent a little; the mineral composition in granite had a relatively large volume, and the cracks initiated from the notch and then propagated to the loading point along the boundary of minerals; its trajectory was distorted, with an obvious feature of intergranular fracture; the looseness of coal was relatively high, the internal joint fissure was fully developed, and the trajectory of its crack propagation was bent; PMMA is one of the transparent media; the trajectory of its crack propagation was straight but showed features of shear failure along the thickness direction.

Figure 7 shows the calculated results for dynamic fracture toughness. By comparing the five rock specimens in the experiment, given the same loading rate, the fracture 

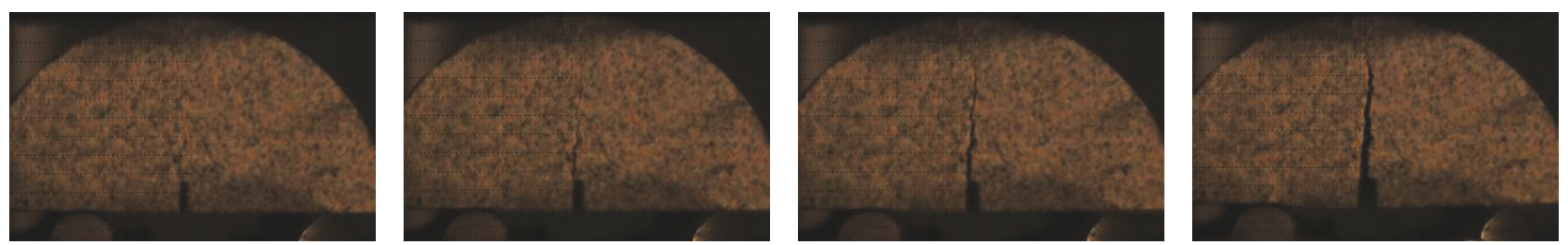

(a) Sandstone
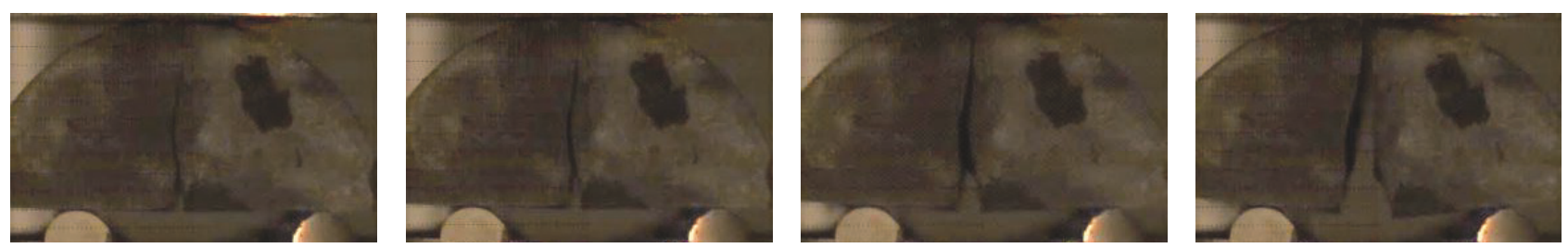

(b) Mudstone
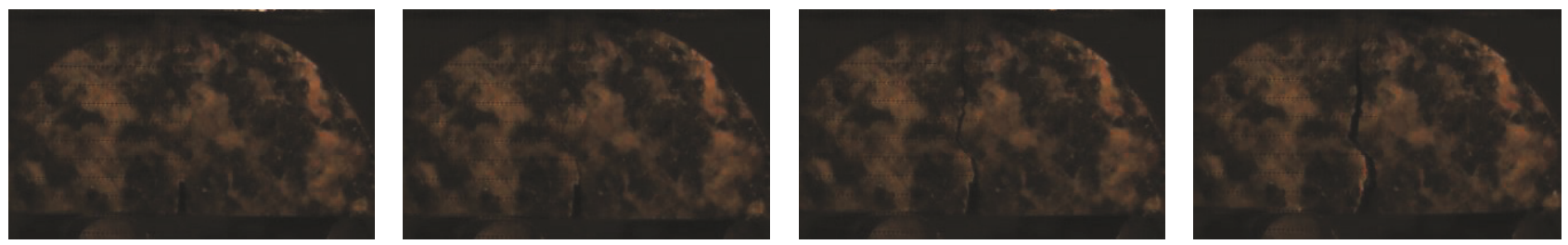

(c) Granite
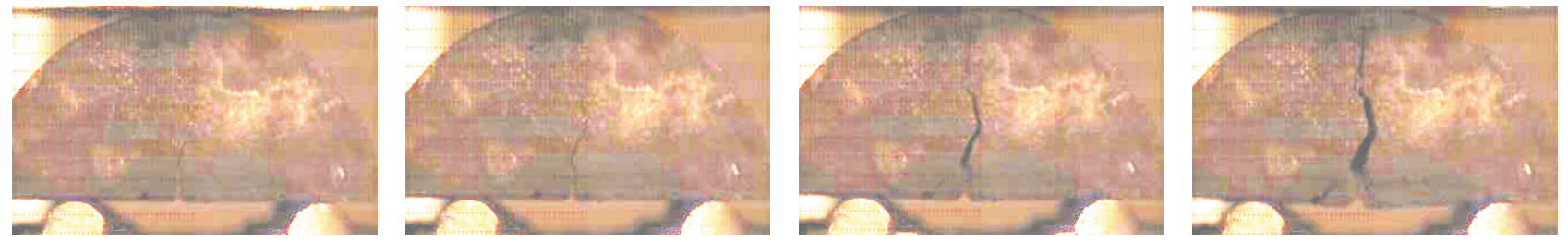

(d) Coal
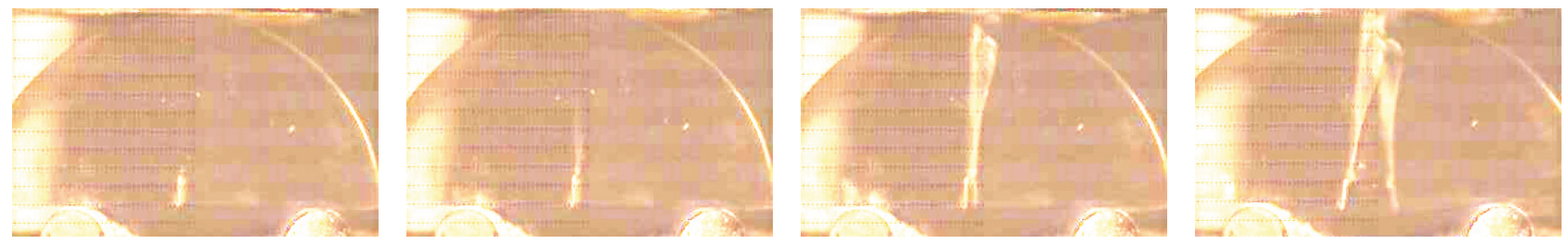

(e) PMMA

FIGURE 6: Process of rock specimen failure.

toughness of granite was the highest, while that of coal was the lowest; sandstone and mudstone had similar results, and that of PMMA was lower than any of these samples, but higher than coal. The dynamic fracture toughness for five rock materials shows a significant loading rate dependency; as the loading rate increases, the dynamic fracture toughness of rock rises gradually. The fracture toughness and loading rate were fit into the linear equation

$$
K_{I C}^{D}=a(m) \dot{K}_{I}+b(m),
$$

where $m$ is the type of rock specimen and $a$ and $b$ are the linear correlation coefficients. Table 2 shows the fitting results.

From Table 2, the slope of the fitting curve for fracture toughness of sandstone, $a$, was the biggest, but the difference $b$ was relatively smaller, which suggests that the change of the fracture toughness of sandstone was the quickest with the increase of loading rate; mudstone and sandstone showed similar characteristics; the difference of fracture toughness fitting curve for granite was the greatest, and the standard deviation for the slope $a$ and the difference $b$ of its fitting curve were the maximum among all rock specimens. And from Figure 7, when the loading rate was low, the increase of fracture toughness was relatively fast; when the loading rate was high, the curve was relatively stable and the increase of fracture toughness was slow, but its linear characteristics were not obvious, which is closely related to the mineral composition of granite; the difference of the fitting curve for fracture toughness of coal, $b$, was the smallest, which is related 
TABLE 1: Physical and mechanical parameters of typical rocks.

\begin{tabular}{|c|c|c|c|c|c|}
\hline & $\begin{array}{l}\text { Density } \\
\left(\mathrm{kg} / \mathrm{m}^{3}\right)\end{array}$ & $\begin{array}{l}\text { Elastic } \\
\text { modulus } \\
(\mathrm{GPa})\end{array}$ & $\begin{array}{l}\text { Poisson's } \\
\text { ratio }\end{array}$ & $\begin{array}{l}\text { Uniaxial } \\
\text { compressive } \\
\text { strength } \\
(\mathrm{MPa})\end{array}$ & Place of Origin \\
\hline Sandstone & 2150 & 4.6 & 0.24 & 41 & $\begin{array}{l}\text { Immediate roof of concentrated } \\
\text { track tunnel, the Second Mining } \\
\text { Area, Shuguang Mine of Shanxi } \\
\text { Coking Coal }\end{array}$ \\
\hline Mudstone & 2480 & 6.5 & 0.25 & 28 & $\begin{array}{l}\text { Immediate floor of concentrated } \\
\text { track tunnel, the Second Mining } \\
\text { Area, Shuguang Mine of Shanxi } \\
\text { Coking Coal }\end{array}$ \\
\hline Granite & 2730 & 18.4 & 0.2 & 103 & $\begin{array}{c}\text { Tongtang Town, Tong'an District, } \\
\text { Xiamen }\end{array}$ \\
\hline Coal & 1475 & 7.9 & 0.23 & 18 & $\begin{array}{l}\text { The Second Mining Area, Shuguang } \\
\text { Mine of Shanxi Coking Coal }\end{array}$ \\
\hline PMMA & 1127 & 6.1 & 0.28 & & Beijing Xuanguang Acrylic Factory \\
\hline
\end{tabular}

TABLE 2: Linear correlation coefficients for the fitting curve of fracture toughness-loading rate.

\begin{tabular}{lcccc}
\hline Rock Type $m$ & $a(\mathrm{~s})$ & $a$ Standard Deviation & $b\left(\mathrm{Mpa} \cdot \mathrm{m}^{1 / 2}\right)$ & $b$ Standard Deviation \\
\hline Sandstone & 0.04049 & 0.00319 & 0.37337 & 0.29452 \\
Mudstone & 0.03785 & 0.00156 & 0.51833 & 0.13249 \\
Granite & 0.02928 & 0.00506 & 2.19798 & 0.45141 \\
Coal & 0.01765 & 0.0026 & 0.28858 & 0.22856 \\
PMMA & 0.01566 & 0.00103 & 1.71827 & 0.10356 \\
\hline
\end{tabular}

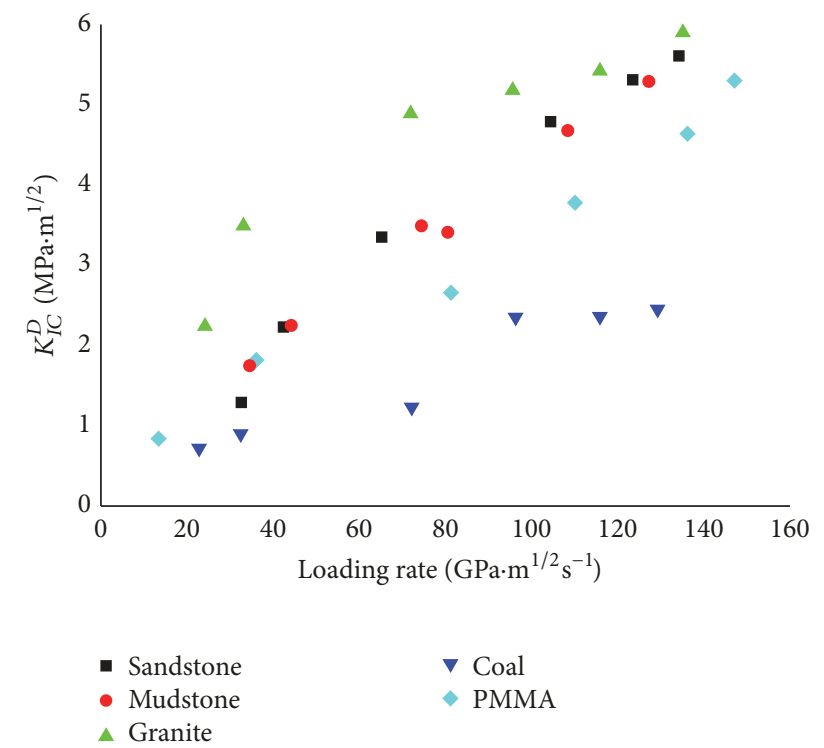

FIGURE 7: Test results of the dynamic fracture toughness for several typical rocks.

to the characteristics of coal itself; the slope of the fitting curve for fracture toughness of PMMA, $a$, was the smallest, but the difference $b$ was relatively higher, which suggests that the fracture toughness of such material was less sensitive to the loading rate, and its fracture toughness would increase linearly and gradually with the loading rate.

\section{DLSM Numeral Simulation-Based Analysis of the Dynamic Fracture Characteristics for Typical Rocks}

In order to examine the dynamic fracture toughness for different rock types, it is necessary to conduct a three-point bending experiment given the same impact rate. However, the SHPB used here was in pressure control; it would be too difficult to control the bullet impact rate at a given value. Furthermore, the total factor test would add to the cost of trials. To address this, DLSM numerical simulation with physical experiment was an alternative approach.

4.1. Discrete Lattice Spring Model (DLSM). In the Discrete Lattice Spring Model (DLSM), the solid medium was represented by a set of particles and connected with a spring [17], and its mechanical responses were demonstrated by the appropriate lattice structure. When the gap among particles was less than the given threshold, the adjacent particles would be connected by the dummy "spring ligament", as shown in Figure 8. Different assembly forms of particles and threshold values would result in different structures of lattice spring. A "ligament" comprises a normal spring and a set of multibody 


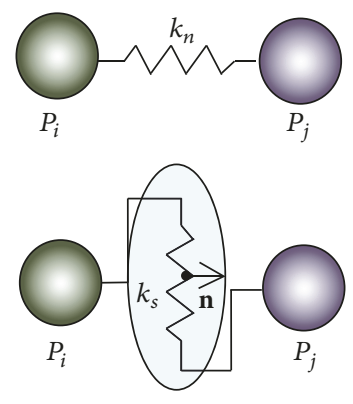

(a) Normal, tangential spring

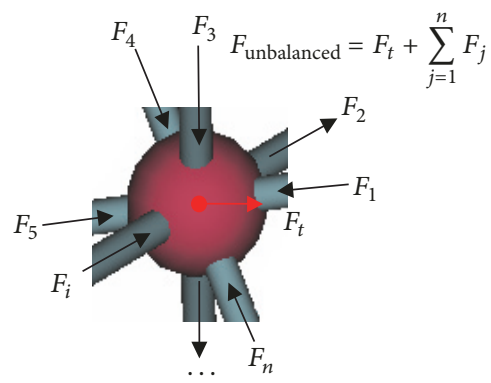

(b) Forces applied on the particle

FIGURE 8: Particles and spring ligament.

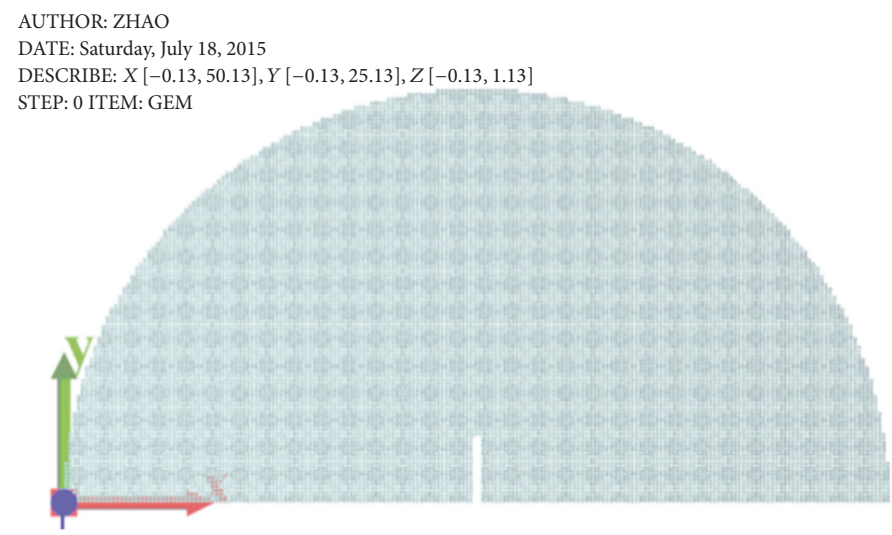

FIGURE 9: Model of NSCB specimen.

tangential springs; DLSM can simulate the short- and longdistance interaction among the particles through a ligament, as shown in Figure 8(a). The specific details about DLSM and the associated validation and application are stated in [17-19].

\subsection{Establishment of the Test Model for Rock Fracture Tough-} ness. Figure 9 shows the DLSM and its size is the same as the actual specimen. The diameter of particle is $0.25 \mathrm{~mm}$ and the whole model is composed of 300,000 particles. The physical and mechanical parameters selected here are the actual parameters of rock, as listed in Table 1, with a spring damage parameter of 0.005 . The dynamic loads in the course of the experiment were characterized by the rate loading applied above the middle part of the specimen, and its loading parameters are

$$
v(t)= \begin{cases}\frac{v_{d} t}{t_{0}}, & \left(t \leq t_{0}\right) \\ v_{d}, & \left(t>t_{0}\right),\end{cases}
$$

where $v_{d}$ is the applied dynamic rate loading, in $\mathrm{mm} / \mathrm{s} ; t_{0}$ is the required time for such rate changing from 0 to the given value, which was selected as $20 \mu$ s for all models. At the initial stage after the loads were applied, the specimen would easily reach a dynamic equilibrium by increasing the amplitude of loads. Such time of increase was usually the time taken for 5 round travels of the stress wave within the specimen, and the loading rate induced by different loading rates may be varied.
4.3. Numerical Calculation Results. Take sandstone as an example; Figure 10 shows the propagation of stress wave from the impact load in the sandstone specimen and the dynamic fracture process of the semicircular three-point bending sample when $v_{d}=4 \mathrm{~m} / \mathrm{s}$; the stress wave propagated from the impact loading point to the lower boundary and reached the notch at $36.25 \mu \mathrm{s}$, when the stress concentration at the notch showed obvious features; at $73.75 \mu$ s, the crack initiated from the tip of the notch. In the DLSM simulation, the propagation morphology of cracks and their displacement characteristics are similar to the actual crack characteristics as shown in the high-speed captures of Figure 6, which also makes up for the deficiency that the process of crack initiation and propagation is incomplete due to low configuration of the high-speed camera. Figure 11 gives the numerical results for mudstone, granite, coal, and PMMA, respectively.

Figure 12 shows the curve of the position of crack tip with time, and the crack propagation can be roughly divided into two stages, namely, the stable propagation at the early stage of crack propagation and the unstable propagation at its late stage. The slope of curve at the stable propagation stage was used as the average velocity for the crack propagation; the majority of average velocities for stable crack propagation in numerical calculation were $350 \mathrm{~m} / \mathrm{s}-400 \mathrm{~m} / \mathrm{s}$, while that of the cracks in coal was about $250 \mathrm{~m} / \mathrm{s}$. The occurrence of unstable propagation stage is attributed to the fact that a large deformation appeared on the specimen and the damage 
AUTHOR: ZHAO

DATE: Friday, May, 22, 2015

DESCRIBE: $X[-0.5,210.5], Y[-0.5,50.25], Z[-0.5,5.25]$ ITEM: EPSX
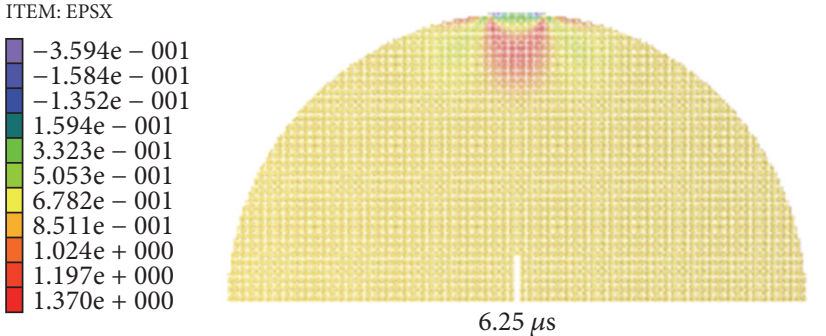

AUTHOR: ZHAO

DATE: Friday, May, 22, 2015

DESCRIBE: $X[-0.5,210.5], Y[-0.5,50.25], Z[-0.5,5.25]$

ITEM: EPSX

$-3.594 \mathrm{e}-001$
$-1.584 \mathrm{e}-001$
$-1.352 \mathrm{e}-001$
$1.594 \mathrm{e}-001$
$3.323 \mathrm{e}-001$
$5.053 \mathrm{e}-001$
$6.782 \mathrm{e}-001$
$8.511 \mathrm{e}-001$
$1.024 \mathrm{e}+000$
$1.197 \mathrm{e}+000$
$1.370 \mathrm{e}+000$

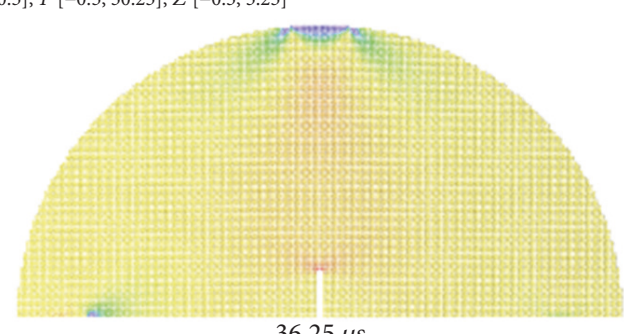

$36.25 \mu \mathrm{s}$

AUTHOR: ZHAO

DATE: Friday, May, 22, 2015

DESCRIBE: $X[-0.5,210.5], Y[-0.5,50.25], Z[-0.5,5.25]$

ITEM:

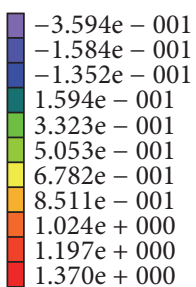

UTHOR: ZHAO

DATE: Friday, May, 22, 2015

DESCRIBE: $X[-0.5,210.5], Y[-0.5,50.25], Z[-0.5,5.25]$

STEP: EPSX

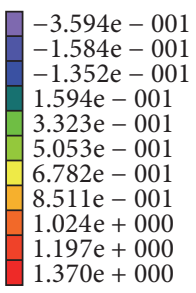

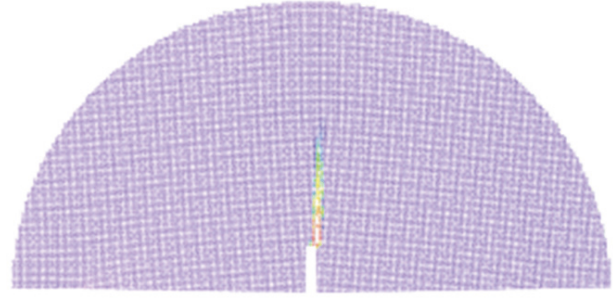

$111.25 \mu \mathrm{s}$
AUTHOR: ZHAO

DATE: Friday, May, 22, 2015

DESCRIBE: $X[-0.5,210.5], Y[-0.5,50.25], Z[-0.5,5.25]$ ITEM: EPSX

\begin{tabular}{|l}
$-3.594 \mathrm{e}-001$ \\
$-1.584 \mathrm{e}-001$ \\
$-1.352 \mathrm{e}-001$ \\
$-1.594 \mathrm{e}-001$ \\
$-3.323 \mathrm{e}-001$ \\
$5.053 \mathrm{e}-001$ \\
$6.782 \mathrm{e}-001$ \\
$8.511 \mathrm{e}-001$ \\
$1.024 \mathrm{e}+000$ \\
$1.197 \mathrm{e}+000$ \\
$1.370 \mathrm{e}+000$
\end{tabular}

AUTHOR: ZHAO

DATE: Friday, May, 22, 2015

DESCRIBE: $X[-0.5,210.5], Y[-0.5,50.25], Z[-0.5,5.25]$ ITEM: EPSX

\begin{tabular}{|l}
$-3.594 \mathrm{e}-001$ \\
$-1.584 \mathrm{e}-001$ \\
$-1.352 \mathrm{e}-001$ \\
\hline $1.594 \mathrm{e}-001$ \\
$-3.323 \mathrm{e}-001$ \\
\hline $5.053 \mathrm{e}-001$ \\
$6.782 \mathrm{e}-001$ \\
$8.511 \mathrm{e}-001$ \\
$1.024 \mathrm{e}+000$ \\
$1.197 \mathrm{e}+000$ \\
$1.370 \mathrm{e}+000$
\end{tabular}

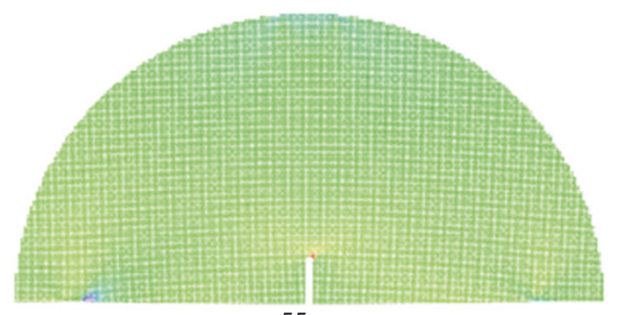

$55 \mu \mathrm{s}$

AUTHOR: ZHAO

DATE: Friday, May, 22, 2015

DESCRIBE: $X[-0.5,210.5], Y[-0.5,50.25], Z[-0.5,5.25]$

ITEM: EPSX
\begin{tabular}{|l}
$-3.594 \mathrm{e}-001$ \\
$-1.584 \mathrm{e}-001$ \\
$-1.352 \mathrm{e}-001$ \\
$1.594 \mathrm{e}-001$ \\
$3.323 \mathrm{e}-001$ \\
$5.053 \mathrm{e}-001$ \\
$6.782 \mathrm{e}-001$ \\
$8.511 \mathrm{e}-001$ \\
$1.024 \mathrm{e}+000$ \\
$1.197 \mathrm{e}+000$ \\
$1.370 \mathrm{e}+000$
\end{tabular}

AUTHOR: ZHAO

DATE: Friday, May, 22, 2015

DESCRIBE: $X[-0.5,210.5], Y[-0.5,50.25], Z[-0.5,5.25]$ ITEM: EPSX

$-3.594 \mathrm{e}-001$
$-1.584 \mathrm{e}-001$
$-1.352 \mathrm{e}-001$
$1.594 \mathrm{e}-001$
$3.323 \mathrm{e}-001$
$-5.053 \mathrm{e}-001$
$6.782 \mathrm{e}-001$
$8.511 \mathrm{e}-001$
$1.024 \mathrm{e}+000$
$1.197 \mathrm{e}+000$
$1.370 \mathrm{e}+000$

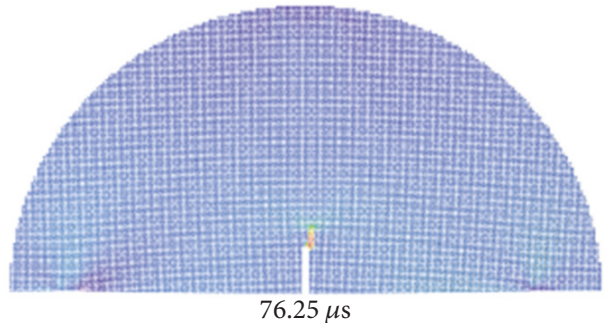

$76.25 \mu \mathrm{s}$

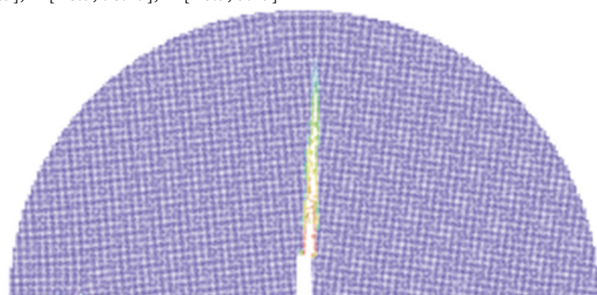

$141.25 \mu \mathrm{s}$

AUTHOR: ZHAO

DATE: Friday, May, 22, 2015

DESCRIBE: $X[-0.5,210.5], Y[-0.5,50.25], Z[-0.5,5.25]$
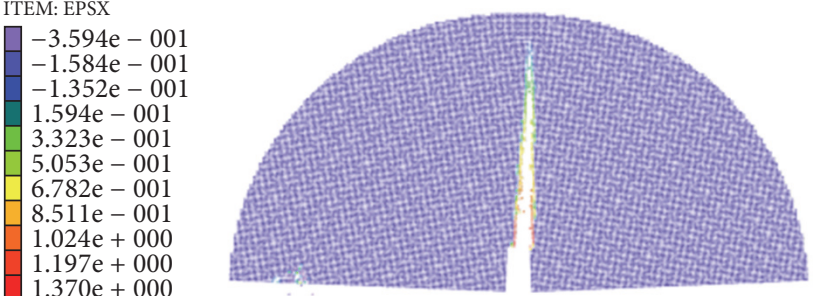

$186.25 \mu \mathrm{s}$

FIGURE 10: Simulation of the rock specimen fracture (sandstone). 
AUTHOR: ZHAO

DATE: Monday, July 20, 2015

DESCRIBE: $X[-0.13,50.13], Y[-0.13,25.13], Z[-0.13,1.13]$

STEP: 160 ITEM: EPSX
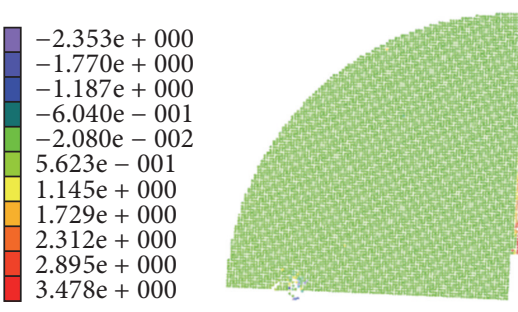

(a) Mudstone

AUTHOR: ZHAO

DATE: Monday, July 20, 2015

DESCRIBE: $X[-0.13,50.13], Y[-0.13,25.13], Z[-0.13,1.13]$

STEP: 160 ITEM: EPSX
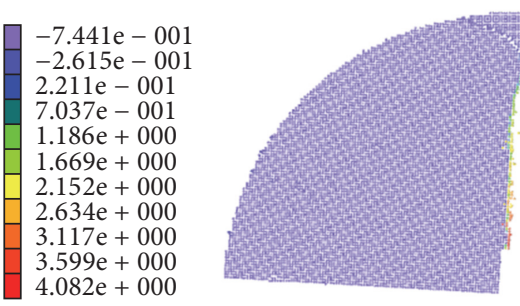

(c) Coal

AUTHOR: ZHAO

DATE: Tuesday, July 21, 2015

DESCRIBE: $X[-0.13,50.13], Y[-0.13,25.13], Z[-0.13,1.13]$

STEP: 134 ITEM: EPSX

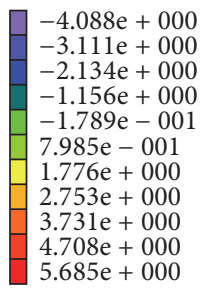

AUTHOR: ZHAO

DATE: Monday, July 20, 2015

DESCRIBE: $X[-0.13,50.13], Y[-0.13,25.13], Z[-0.13,1.13]$

STEP: 137 ITEM: EPSX

FIGURE 11: DLSM calculated results for the other four rock specimens.

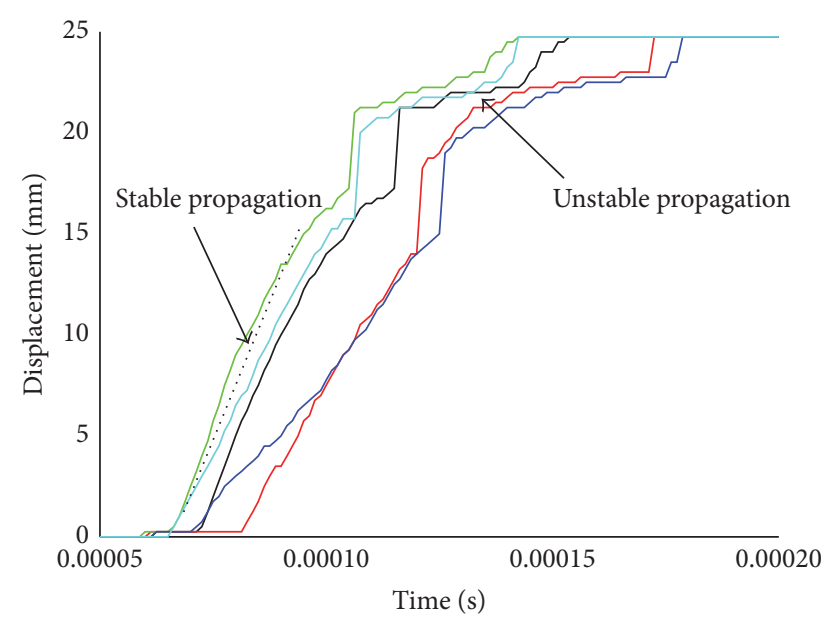

$\begin{array}{ll}\text { - Sandstone } & \text { Coal } \\ \text { Mudstone } & \text { Cranite }\end{array}$

FIGURE 12: Displacement-time curve for the crack propagation, $v_{d}=$ $4 \mathrm{~m} / \mathrm{s}$.

of particles was not regular anymore at the late stage of numerical calculation.

Figure 13 shows the loading force-displacement curves which are typical unimodal smooth. The peak point in each curve was used as the value for $P(t)_{\max }$, which was substituted into (2) for the calculation of dynamic fracture toughness.

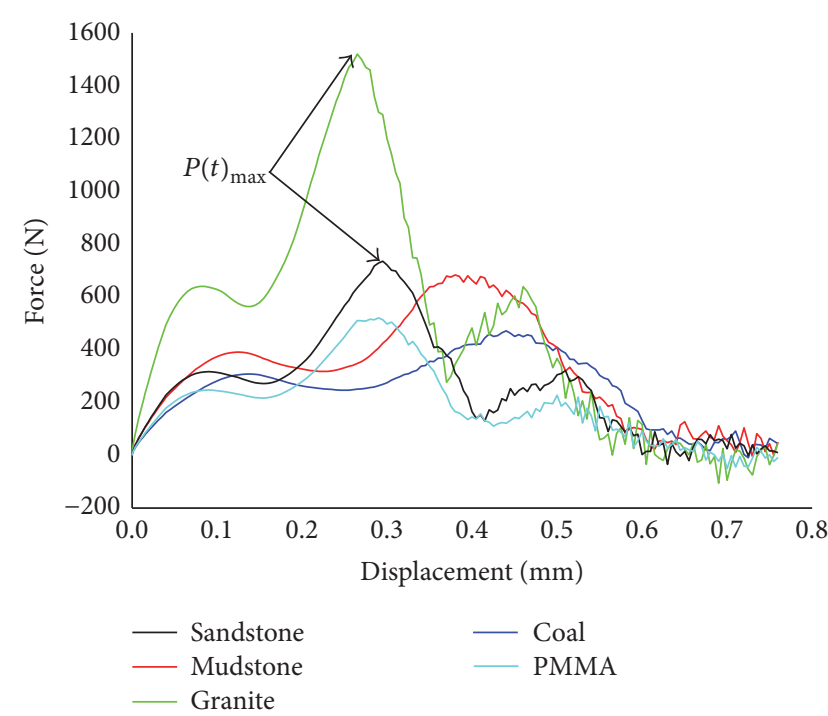

FIgURE 13: Loading force-displacement curve, $v_{d}=4 \mathrm{~m} / \mathrm{s}$.

Figure 14 shows when $v_{d}=4 \mathrm{~m} / \mathrm{s}, 6 \mathrm{~m} / \mathrm{s}, 8 \mathrm{~m} / \mathrm{s}, 12 \mathrm{~m} / \mathrm{s}, 14 \mathrm{~m} / \mathrm{s}$, $16 \mathrm{~m} / \mathrm{s}, 18 \mathrm{~m} / \mathrm{s}$, or $20 \mathrm{~m} / \mathrm{s}$, the dynamic fracture toughness corresponding to each type of rock. When the impact velocity exceeded a certain value, the damage on rock specimen firstly occurred at the part where the load was applied, rather than at the tip of the notch. For example, Figure 15 shows that when $v_{d}>10 \mathrm{~m} / \mathrm{s}$, the loading point of coal specimen was firstly damaged; when $v_{d}>18 \mathrm{~m} / \mathrm{s}$, the sandstone and 


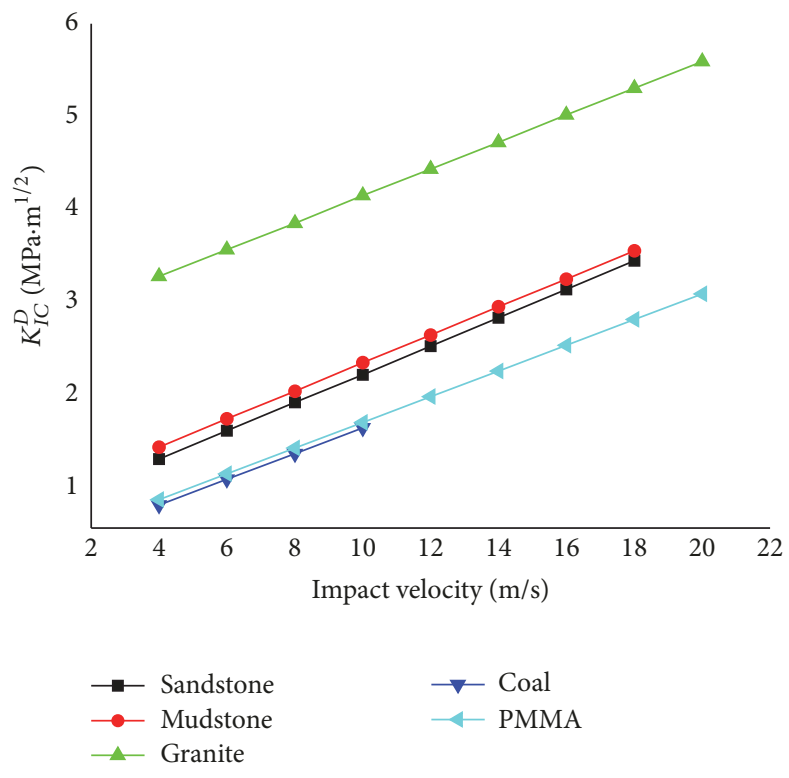

Figure 14: DLSM calculated results of the fracture toughness.

AUTHOR: ZHAO

DATE: Monday, July 20, 2015

DESCRIBE: $X[-0.13,50.13], Y[-0.13,25.13], Z[-0.13,1.13]$ STEP: 57 ITEM: BROKEN
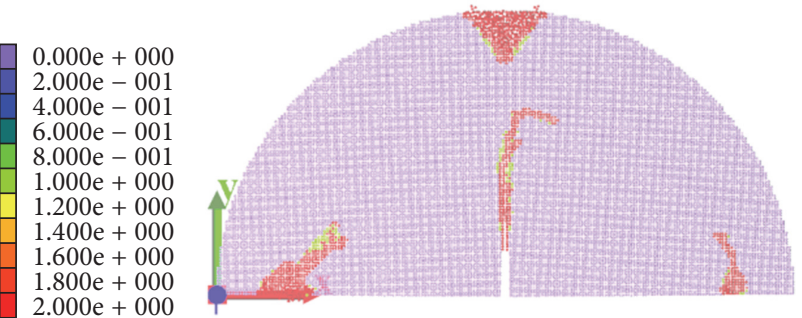

(a) Coal: $v_{d}=12 \mathrm{~m} / \mathrm{s}$

AUTHOR: ZHAO

DATE: Monday, July 20, 2015

DESCRIBE: $X[-0.13,50.13], Y[-0.13,25.13], Z[-0.13,1.13]$ STEP: 160 ITEM: BROKEN

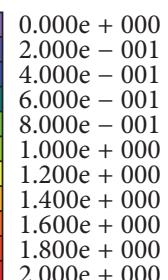

$1.800 \mathrm{e}+000$
$2.000 \mathrm{e}+000$

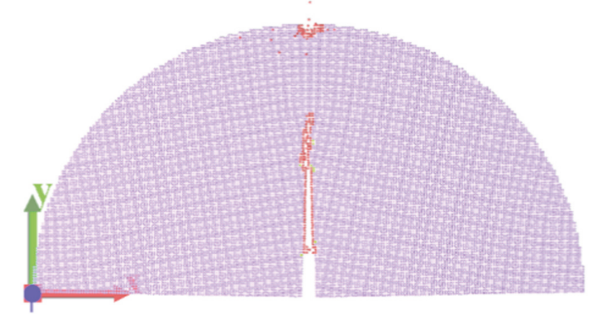

(b) Granite: $v_{d}=22 \mathrm{~m} / \mathrm{s}$

FIGURE 15: Damage morphology of partial rock specimens.

mudstone specimens also showed a similar case. This suggests that, with such impact velocity, the dynamic semicircular three-point bending experiment will be unsuitable to obtain the dynamic fracture toughness of rock. Numerical results show that the dynamic fracture toughness of rock specimen increased linearly with the loading rate; given the same impact rate, the dynamic fracture toughness of granite was the greatest, while it was the smallest for coal; that of the sandstone and mudstone was between the values and their fracture toughness was similar; the fracture toughness of PMMA was greater than coal but less than rock.

4.3.1. Effect of the Loading Area. In the course of SHPB experiment, the part where the input bar impacted the specimen can be considered as the linear loading, namely, the top of the upper boundary of the arc contacted with the input bar. However, in the course of the actual experiment, when the input bar was applied to the specimen, the upper boundary of the arc was firstly under pressure, which means that the dynamic loading was actually applied to a very small plane, but the exact area of such plane remains to be identified.

With respect to the problems stated above, take the sandstone as an example; the DLSM for each of the four different loading areas was established as shown in Figure 16, where (a) is the free face loading, namely, the above simulations used this method; (b) is the approximately linear loading, in which the loading face is only $1 \mathrm{~mm}$ long; (c) surface loading, the loading surface was $2 \mathrm{~mm}$ long; (d) surface loading, the loading surface was $5 \mathrm{~mm}$ long; $v_{d}=4 \mathrm{~m} / \mathrm{s}$.

Figure 17 shows the DLSM calculated results. The calculated results in case of the free face loading and the $5 \mathrm{~mm}$ surface loading are in good consistency with the experiment; the specimen was symmetrically split into two parts; only the particles near the left support were damaged when the splitting process was about to end, which is consistent with the reality. At the late stage of SHPB experiment, the input bar was continuously pressed to the broken specimen at 


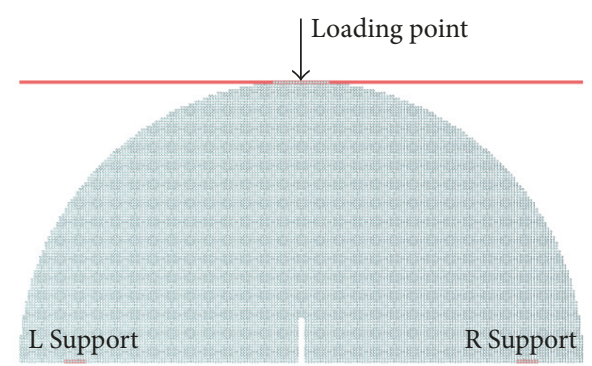

(a)

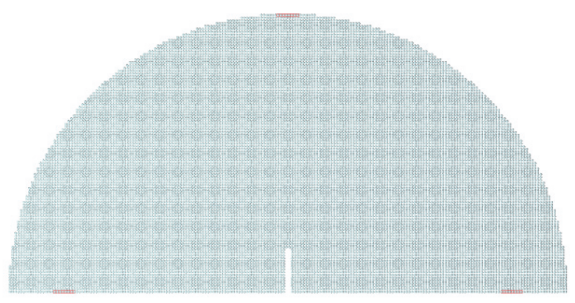

(c)

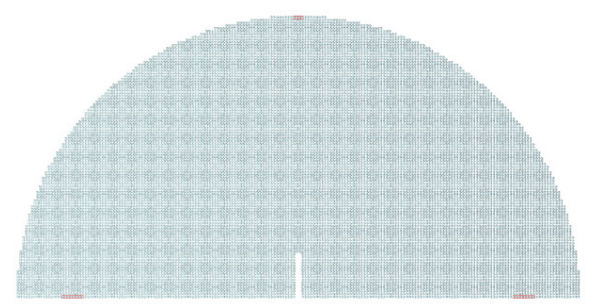

(b)

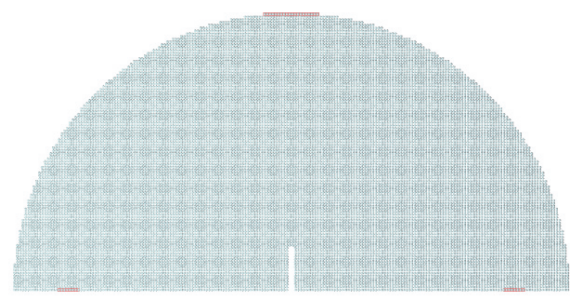

(d)

FIGURE 16: Four DLSMs for each of the four different loading areas.
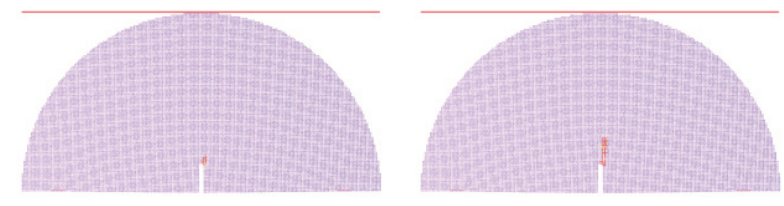

(a)
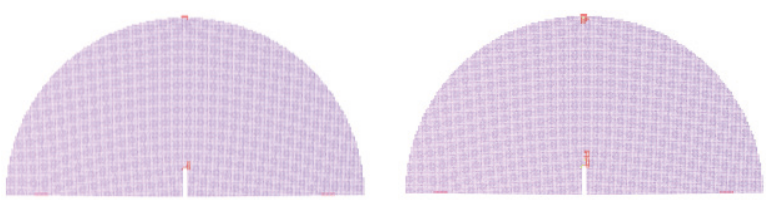

(b)
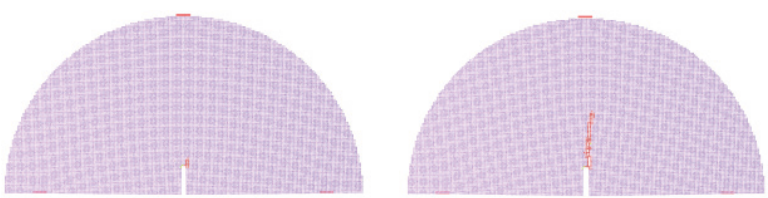

(c)
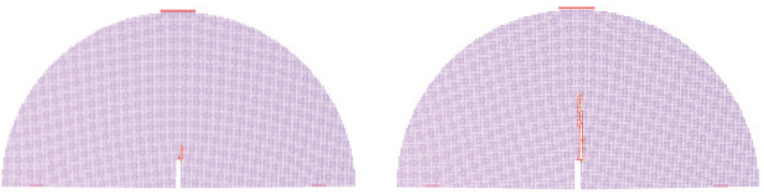
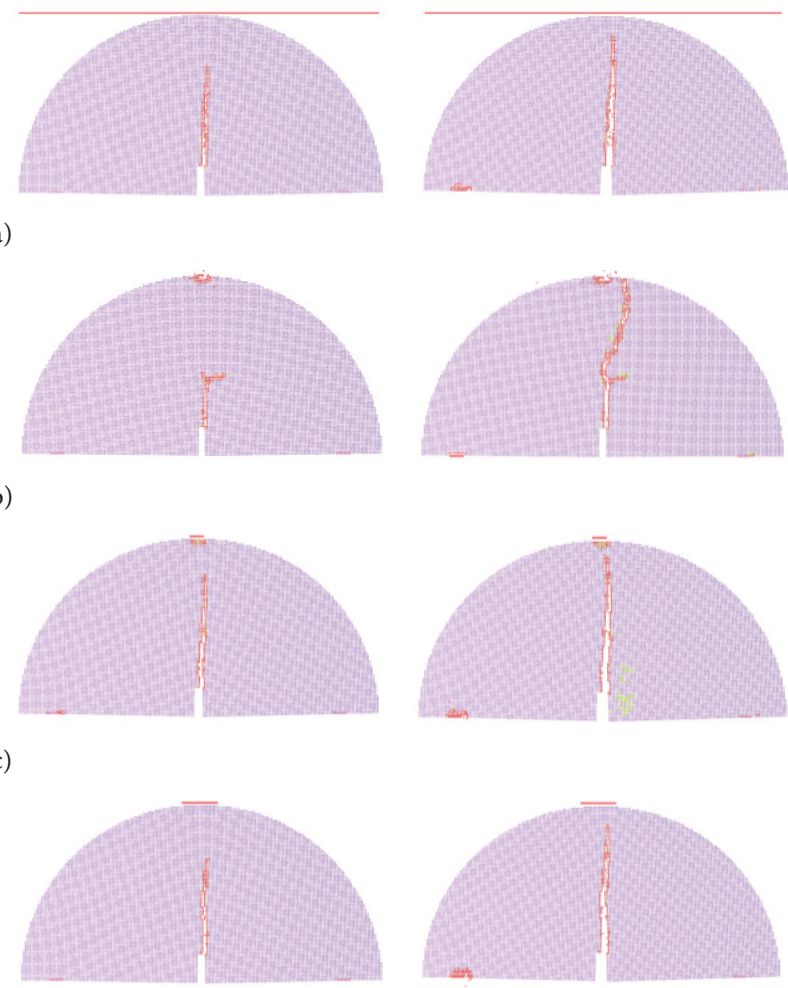

(d)

FIGURE 17: DLSM calculated results.

a high speed, and the support became the point of stress concentration, which will be absolutely damaged. In case of the $2 \mathrm{~mm}$ surface loading, the fracture began from the notch, but as the crack propagated, the particles at the loading point were also damaged. Because the basic specimen had been damaged, due to the relatively small area of the loading end, the stress concentration was still very obvious. In case of the linear loading, although the fracture began from the notch, as soon as the crack initiated, the particles at the loading point were also damaged, and as the crack propagated, the crack tip generated two branches; the crack finally became distorted, until it ended at the right end of the loading point. 
TABLE 3: Support restraints.

\begin{tabular}{|c|c|c|c|c|c|}
\hline \multirow{2}{*}{ No. } & \multicolumn{2}{|c|}{ L Support } & \multicolumn{2}{|c|}{ R Support } & \multirow{2}{*}{ Remark } \\
\hline & $X$-direction & $Y$-direction & $X$-direction & $Y$-direction & \\
\hline I & 0 & 0 & - & 0 & $\begin{array}{l}\text { L Support was fixed, while } \\
\text { R Support was smooth }\end{array}$ \\
\hline II & 0 & 0 & 0 & 0 & $\begin{array}{c}\text { Two supports were fully } \\
\text { fixed }\end{array}$ \\
\hline III & - & 0 & - & 0 & $\begin{array}{l}\text { Two supports were fully } \\
\text { smooth in } X \text {-direction, } \\
\text { while being restrained in } \\
Y \text {-direction }\end{array}$ \\
\hline
\end{tabular}

"0" means that the velocity was zero; "-" means that there was no restraint.

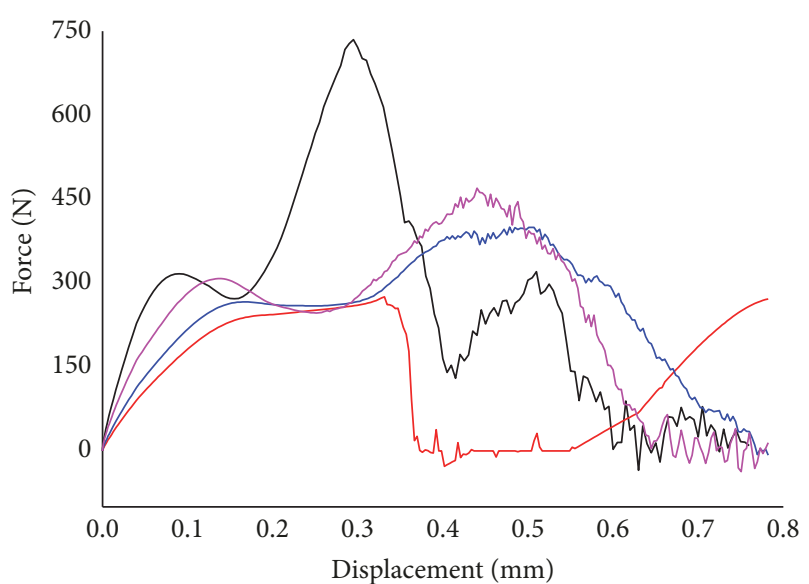

$\begin{array}{ll}\text { — Free face loading } & \text { - Surface loading, } 2 \mathrm{~mm} \\ \text { - Linear loading } & \text { Surface loading, } 5 \mathrm{~mm}\end{array}$

FIGURE 18: Displacement-loading curve.

From the displacement-loading curve in Figure 18, as the displacement increased, the load at the time of linear loading increased to a certain value and then entered the stage of "plastic platform", followed by the rapid reduction to zero; when the displacement continued to increase, the load increased again, which indicates that the semicircular threepoint bending dynamic fracture experiment with the linear loading will be unsuitable to obtain the dynamic fracture toughness of rock. From the curve, it also shows that, with the decrease of loading area, the time when the loading peak occurs gradually delayed, along with the gradual reduction of peak value. From the displacement-time curve in Figure 19, once the loading point at the upper boundary was damaged, the displacement curve will "jump"; the software failed to induce the curve of crack tip position automatically; for instance, in case of the $2 \mathrm{~mm}$ loading face, at $116 \mu \mathrm{s}$, the loading point had a fracture and the displacement curve would exhibit an error, but it does not affect the calculation of fracture toughness, because the stress value as soon as the crack initiated at the notch was regarded as the peak value of loading force, and then the appropriate fracture toughness can be calculated.

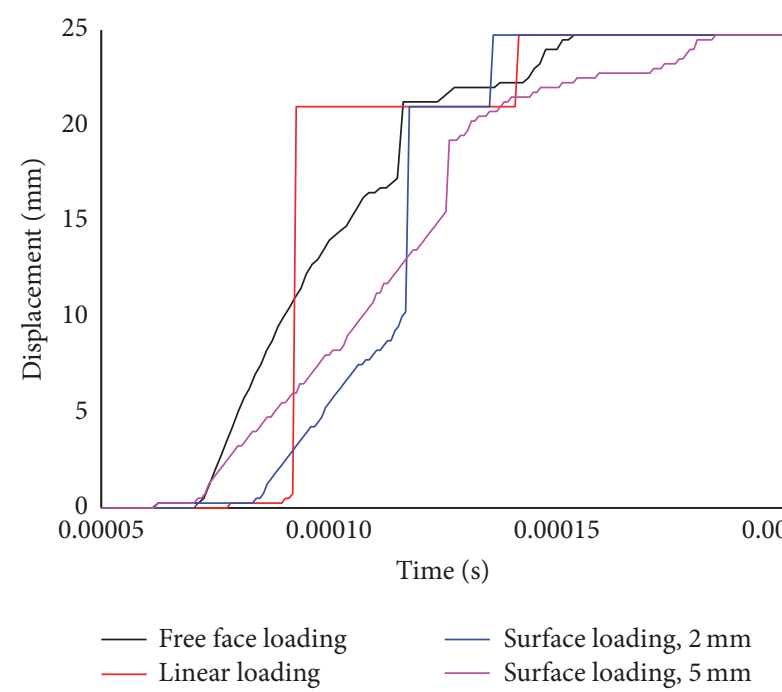

Figure 19: Displacement-time curve.

4.3.2. Effect of the Support Restraints. In the course of DLSM simulation three-point bending experiment, the necessary boundary restraints should be added to the two supports, as shown in Figure 16(a) (L Support, R Support); different restraints may incur an unexpected effect on the calculated results. To examine the effect of support restraints on dynamic fracture toughness test, three different DLSMs were established for the sandstone experiment and Table 3 shows its boundary restraints, in which Scheme I is the support restraints as mentioned earlier.

Figure 20 shows the numerical results of the different restraints, in which the results of Scheme I are as shown in Figure 17(a) and they are not mentioned again. In Scheme II, although the crack initiated at the notch but did not propagate, there was a fracture at the loading point and the range of such fracture expanded continuously; the crack began to propagate from the notch in a "herringbone" shape. In Scheme III, the crack was gradually branched into two cracks to run through the specimen, after it propagated with certain distance. Since these fracture morphologies are inconsistent with the experiment, the fracture toughness cannot be calculated accordingly, which also indicates that 

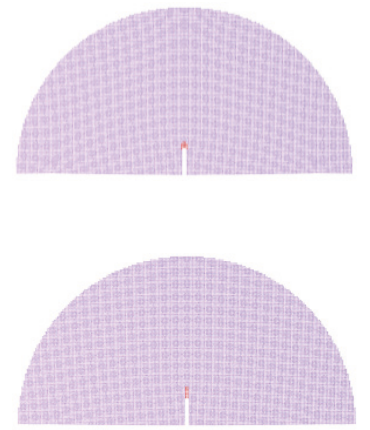
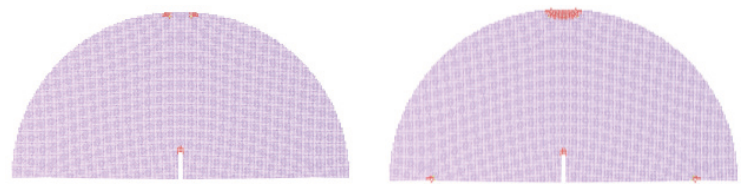

(a) II
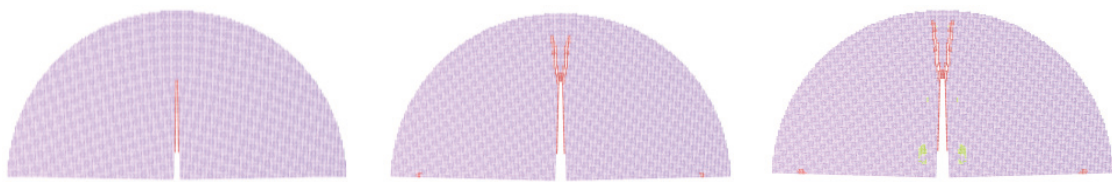

(b) III

FIGURE 20: Numerical results for different restraints.

the support restraints will have a significant effect on the calculated results.

\section{Conclusion}

The dynamic fracture toughness of several typical rock materials including sandstone in normal state was studied using NSCB-recommended test method and SHPB experiment system, with high-speed photography and DLSM numerical analysis. The following conclusions can be drawn.

The dynamic fracture toughness of rock materials showed an obvious loading rate dependency and the loading rate tended to be positively correlated with the dynamic fracture toughness of rock. Through this experiment, given the same loading rate, the fracture toughness of granite was the highest, while it was the lowest for coal; sandstone and mudstone had similar results, and that of PMMA was lower than any of these samples, but higher than coal.

DLSM numerical results are also similar to the test results. With the increase of the bullet impact loading rate, the dynamic fracture toughness increased linearly; when the impact velocity exceeded a certain value, the damage on rock specimen firstly occurred at the part where the load was applied, rather than at the tip of notch. In this case, the dynamic fracture toughness of rock cannot be calculated correctly. The loading face had a significant effect on the tested results; an ideal linear loading would be unsuitable to the dynamic fracture toughness test of rock materials, but the numerical results in case of the free face loading and the $5 \mathrm{~mm}$ surface loading were in good consistency with the experiment. The restraints at the bottom support will also affect the test. Since the numerical simulation results in case of "two supports are fully fixed" and "two supports are fully smooth in $X$-direction, while restrained in $Y$-direction" were inconsistent with the experiment, the fracture toughness cannot be calculated accordingly.

As for the dynamic fracture toughness test of rock, the tips of prefabricated small notch should be as sharp as possible. We can try to change the shape of the end of the incident bar. Perhaps we can design an arc section.

\section{Conflicts of Interest}

The author declares that there are no conflicts of interest regarding the publication of this paper.

\section{Acknowledgments}

The author would like to thank Dr. Gao-feng Zhao for the help in performing the DLSM numerical simulation and the National Natural Science Foundation of China (no. 51704295) and Project funded by China Postdoctoral Science Foundation (2016M600147) for their support.

\section{References}

[1] R.-S. Yang, Y.-B. Wang, Z.-W. Yue, and G.-Q. Liu, "Dynamic behaviors of crack propagation in directional fracture blasting with two holes," Explosion and Shock Waves, vol. 33, no. 6, pp. 631-637, 2013.

[2] R. Yang, Y. Wang, and C. Ding, "Laboratory study of wave propagation due to explosion in a jointed medium," International Journal of Rock Mechanics and Mining Sciences, vol. 81, pp. 7078, 2016.

[3] N. Li, L.-J. Chen, and P. Zhang, "Dynamic analysis for fracturing progress by detonation gas," Chinese Journal of Geotechnical Engineering, vol. 28, no. 4, pp. 460-463, 2006.

[4] R. Yang, Y. Wang, L. Hou, and L. Yang, "DLDC experiment on crack propagation in defective medium under impact loading," Chinese Journal of Rock Mechanics and Engineering, vol. 33, no. 10, pp. 1971-1976, 2014.

[5] R.-S. Yang, Y.-B. Wang, H.-J. Xue, and K. Liu, “SEM experiment of rock crack cross section morphology after explosion fracturing with slotted cartridge," Journal of China University of Mining and Technology, vol. 42, no. 3, pp. 337-341, 2013.

[6] L. Yang, R. Yang, X. Zhao et al., "Experimental investigation on dynamic fractures of some metamorphic rock using reflected caustics," Chinese Journal of Rock Mechanics and Engineering, vol. 34, no. 4, pp. 779-786, 2015.

[7] Y. X. Zhou, K. Xia, X. B. Li et al., "Suggested methods for determining the dynamic strength parameters and mode-I fracture toughness of rock materials," International Journal of Rock Mechanics and Mining Sciences, vol. 49, pp. 105-112, 2012. 
[8] M.-D. Wei, F. Dai, N.-W. Xu, T. Zhao, and Y. Liu, "An experimental and theoretical assessment of semi-circular bend specimens with chevron and straight-through notches for mode I fracture toughness testing of rocks," International Journal of Rock Mechanics and Mining Sciences, vol. 99, pp. 28-38, 2017.

[9] Y. Wang and R. Yang, "Study of the dynamic fracture characteristics of coal with a bedding structure based on the NSCB impact test," Engineering Fracture Mechanics, vol. 184, pp. 319338, 2017.

[10] W. Yao, Y. Xu, H.-W. Liu, and K. Xia, "Quantification of thermally induced damage and its effect on dynamic fracture toughness of two mortars," Engineering Fracture Mechanics, vol. 169, pp. 74-88, 2017.

[11] R. Chen, K. Li, K. Xia, Y. Lin, W. Yao, and F. Lu, "Dynamic Fracture Properties of Rocks Subjected to Static Pre-load Using Notched Semi-circular Bend Method," Rock Mechanics and Rock Engineering, vol. 49, no. 10, pp. 3865-3872, 2016.

[12] M.-D. Wei, F. Dai, N.-W. Xu, J.-F. Liu, and Y. Xu, "Experimental and numerical study on the cracked chevron notched semicircular bend method for characterizing the mode I fracture toughness of rocks," Rock Mechanics and Rock Engineering, vol. 49, no. 5, pp. 1595-1609, 2016.

[13] G. Gao, S. Huang, K. Xia, and Z. Li, "Application of Digital Image Correlation (DIC) in Dynamic Notched Semi-Circular Bend (NSCB) tests," Experimental Mechanics, vol. 55, no. 1, pp. 95-104, 2015.

[14] F. Dai, K. Xia, and M. H. B. Nasseri, "Micromechanical model for the rate dependence of the fracture toughness anisotropy of Barre granite," International Journal of Rock Mechanics and Mining Sciences, vol. 63, pp. 113-121, 2013.

[15] T. Yin, X. Li, K. Xia, and S. Huang, "Effect of thermal treatment on the dynamic fracture toughness of laurentian granite," Rock Mechanics and Rock Engineering, vol. 45, no. 6, pp. 1087-1094, 2012.

[16] Y. Zhao, G.-F. Zhao, Y. Jiang, D. Elsworth, and Y. Huang, "Effects of bedding on the dynamic indirect tensile strength of coal: Laboratory experiments and numerical simulation," International Journal of Coal Geology, vol. 132, pp. 81-93, 2014.

[17] G. F. Zhao, Development of micro-macro continuum-discontinuum coupled numerical method [Ph.D. thesis], EPFL, Switzerland, 2010.

[18] G.-F. Zhao, J. Fang, and J. Zhao, "A 3D distinct lattice spring model for elasticity and dynamic failure," International Journal for Numerical and Analytical Methods in Geomechanics, vol. 35, no. 8, pp. 859-885, 2011.

[19] Y. Zhao, G.-F. Zhao, and Y. Jiang, "Experimental and numerical modelling investigation on fracturing in coal under impact loads," International Journal of Fracture, vol. 183, no. 1, pp. 6380, 2013. 


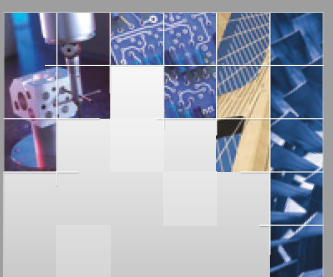

\section{Enfincering}
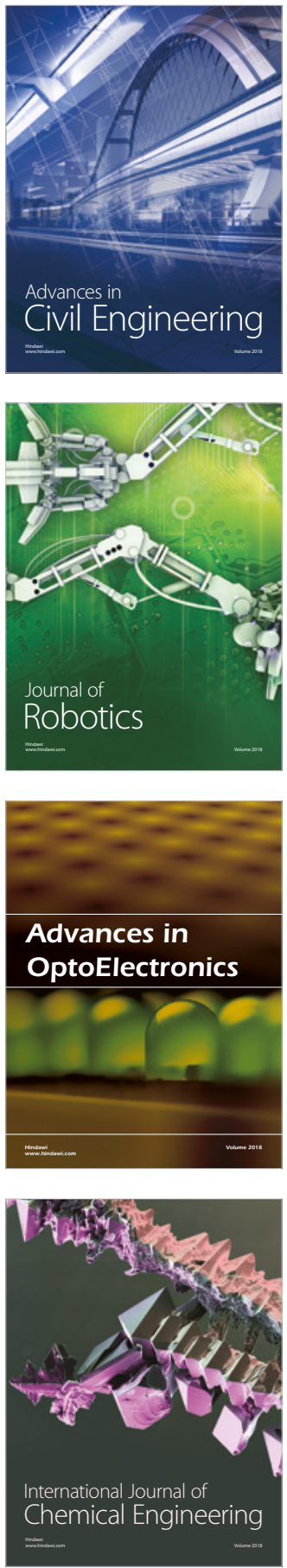

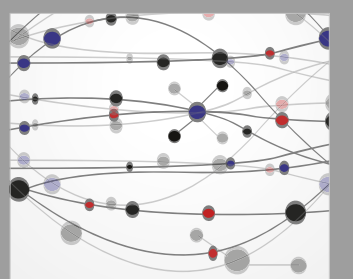

\section{Rotating \\ Machinery}

The Scientific World Journal

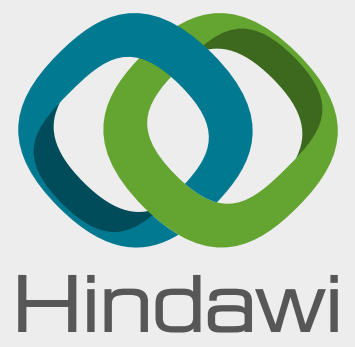

Submit your manuscripts at

www.hindawi.com
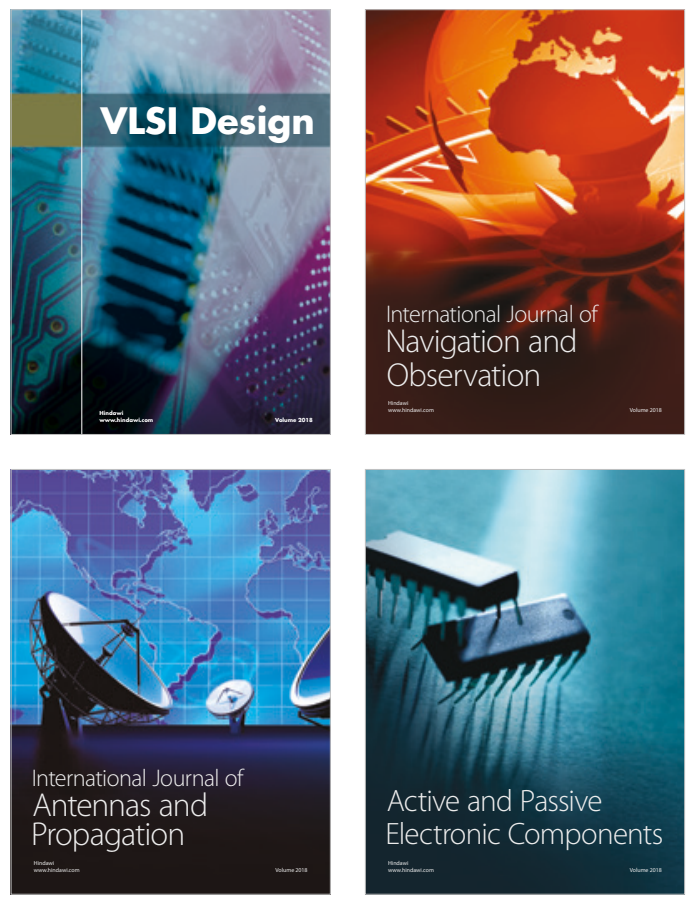
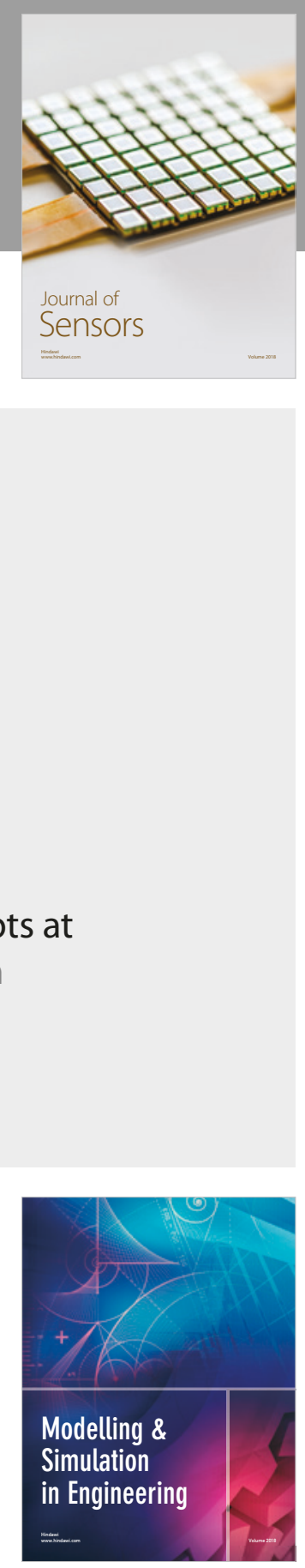

\section{Advances \\ Multimedia}
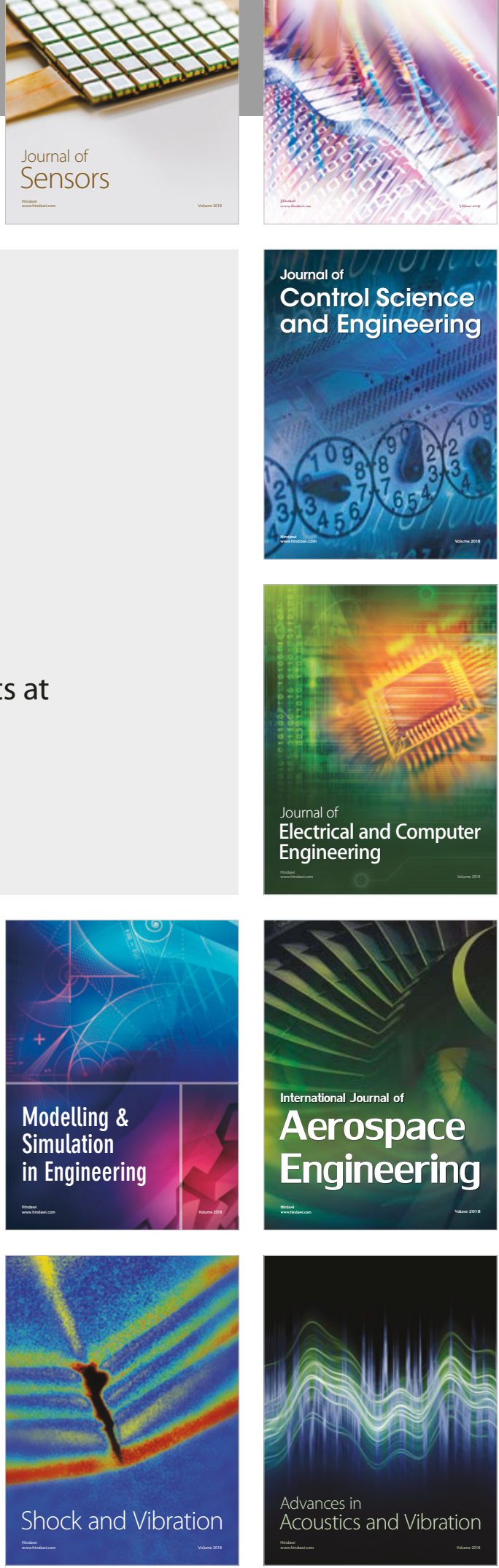